\title{
Is there a link between wealth inequality and deception? - An experimental analysis of different subject pools
}

If everything's the same, then there aren't any choices! I want to wake up in the morning and decide things!

(Lois Lowry, 1993: The Giver)

\begin{abstract}
This paper investigates experimentally the relationship between inequality in initial wealth and deception. Our basic design is adopted from Gneezy (2005): two players interact in a deception game. It is common knowledge that player 1 has private information about the payoffs for both players of two alternative actions. Player 1 sends a message to player 2, indicating which alternative putatively will end up in a higher payoff for player 2. The message, which can either be true or false, does not affect the payoffs of the players. Player 2 has no information about the payoffs. However, player 2 selects one of the two alternatives A or B, which is payoff-relevant for both players. We extend Gneezy (2005) by two elements. First, we systematically vary the initial wealth of the players 1 and 2 (common knowledge to both of them). Second, we do not limit ourselves to the standard population of university students but also recruit chess players that are not enrolled in any degree program. Doing so, we want to find out if our results remain robust over a nonstandard subject population which is known to be experienced to some extent in strategic interactions.
\end{abstract}

\section{Keywords}

Deception; wealth inequality; experimental subjects; cheap talk; asymmetric information

JEL

C91 Laboratory, Individual Behavior

D01 Microeconomic Behavior: Underlying Principles

D31 Personal Income, Wealth, and Their Distributions

Grüner-Khassine: Is there a link between wealth inequality and deception? - 


\section{Behavioral research questions}

The research questions depend on the underlying concept of man. A rational profit maximizer is often used as a benchmark for actual human behavior. However, we would like to discuss the research questions primarily on the basis of a more comprehensive model of man.

We assume that individuals do not only want to achieve high payoffs but also have non-negligible preferences about the distribution of wealth. Following Fehr and Schmidt (1999), we assume that there are three determinants that are (potentially) relevant for the utility function of an individual: $\operatorname{Ui}(\mathrm{x})=\mathrm{xi}-\mathrm{a}^{*}|\mathrm{xi}-\mathrm{xj}, 0|$ - $b^{*}|x j-x i, 0|$, xi denotes own payoffs, $|x i-x j|$ describes monetary advantageous inequality, and |xj-xi| denotes monetary disadvantageous inequality. In other words, individuals dislike inequality. From a psychological point of view, it seems plausible to assume that $b>$ a holds true, i.e. that inequality is perceived more unpleasantly if one is in a monetarily disadvantageous situation. In our research questions (incl. our educated guess about what we expect the experimental subjects to do) we distinguish between sender behavior (i.e. the sender of the message, player 1) and receiver behavior (i.e. the receiver of the message, player 2).

\subsection{Sender behavior}

\section{To what extent does player 1 resort to honest behaviors in the reference scenarios?}

A rational profit-maximizing agent favors $\mathrm{B}$ in situation 1 and $\mathrm{A}$ in situation 2 . Both options generate a monetary surplus of $€ 1$ for player $1 .{ }^{1}$ However, experimental studies of comparable contexts indicate that individuals are quite willing to forego money-maximizing alternatives (for example when there are violations of social norms; Fehr and Gächter 2000, Herrmann et al. 2008). Humans have multiple goals (Simon 1957). These include an aversion to inequality or allocations perceived as unfair. The honest player 1 proposes in situation 1 an option of action which costs $€ 1$ for himself but increases the outcome for player 2 by $€ 9$ (altruistic renunciation). Honesty in situation 2 is associated with a message that would lead to a higher monetary outcome for both players. However, the benefit for player 1 amounts to only $€ 1$ while the other player receives a plus of $€ 10$. Player 1 may find this unjustified and decides to forego the $€ 1$ by choosing the egalitarian action option B (costly punishment). Since the decision of player 2 is payoff-relevant, the expectations of player 1 about whether player 2 follows the message or not plays a role. In his experimental study, Gneezy (2005) found that slightly more than 80\% [82] of the subjects in the role of player 1 have had the expectation that the other player follows the message.

\section{How does the variation of the initial wealth affect the selection of honest alternatives of action?}

Systematic variation of the initial wealth creates inequality. Following Fehr and Schmidt (1999), we assume that inequality is perceived as unpleasant to some extent. This may influence expectations about the opponent's behavior.

I. In treatment 1 , player 1 has an initial wealth of $€ 10$; player 2 has $€ 0$. This surplus may lead to some psychological costs for player 1 due to inequality aversion or fairness preferences. As a result, player 1 is probably more willing to opt for pro-social options (compared to the reference scenario). In addition, player 1 may expect that player 2 trusts player 1 more (in a slightly more formal expression: player 1 expects that player 2 thinks that player 1 is willing to share a small fraction of the larger cake and therefore player 2 tends to follow the message of player 1). Thus, we assume that player 1 behaves more honestly than in the benchmark scenario. In other words: in situation 1,

\footnotetext{
${ }^{1}$ This applies to the entire experiment, i.e. irrespective of the treatments.

Grüner-Khassine: Is there a link between wealth inequality and deception? -
}

An experimental analysis of different subject pools 
player 1 is more inclined to give up a small amount in order to prevent player 2 from being significantly worse off; in situation 2, player 1 is less inclined to propose option B (i.e. the egalitarian outcome), which is significantly monetarily detrimental to player 2 .

II. In treatment 2, player 1 has an initial wealth of $€ 0$; player 2 has $€ 10$. This gap is probably perceived by player 1 as unpleasant (e.g. unjust or unfair). Player 1 might compensate this with a (compared to the benchmark scenario) reduced willingness to welcome a relatively high payoff for player 2 . In other words, player 1 is more willing to lie (i.e. declare option B advantageous in both decision situations).

\section{Do non-students act as if they were more honest than students?}

Various studies point out that non-students tend to be more pro-social than students (Alatas et al. 2009; Belot et al. 2010; Anderson et al. 2013; Falk, Meier and Zehnder 2013; Camerer 2015). Greater pro-sociality towards the opponent means that player 1 increasingly falls back on honest alternatives of action: In situation 1, player 1 renounces $€ 1$ so that the opponent does not perform significantly worse; in situation 2, player 1 accepts inequality in which the opponent performs significantly better (instead of sacrificing $€ 1$ for equality).

\section{What other determinants can explain the decision-making behavior of player 1 ?}

The first 3 research questions dealt with the variables expectation of the behavior of the opponent, treatment 2 , treatment 3 , and the population of interest (students vs. non-students). Now a bunch of other associations between the propensity to be honest and the following variables will be examined: victim sensitivity, beneficiary sensitivity, religiosity, interpersonal trust, gender, political view, age, and net income.

The perception of injustice and the reaction to injustice differs between people (Schmitt et al. 2009). We investigate the individual perceived disutility when others are undeservingly better off than one-self (victim sensitivity) and when one-self is better off for no reasons (beneficiary sensitivity). The effect of religiosity cannot be determined unequivocally ex-ante. For example, Berggren and Bjørnskov (2011) present theoretical arguments for both positive and negative effects. Religiosity can promote that one is more cooperative towards other people (i.e. doing something good for others) as well as being intolerant towards people with a different background. Interpersonal trust matters for the performance of institutions. For example, Dyer and Chu (2003) describe a negative relationship between trust and transaction costs. Experiences with other people may play a role in whether one is more pessimistic or optimistic about other people. Various studies describe differences in gender: Fehr et al. (2006) find that women are more egalitarian than men; Croson and Gneezy (2009) summarize in their literature review that women tend to be on average more risk-averse than men. With regard to the relevance of political views, Fehr et al. (2006) "surprisingly" find no noteworthy differences between people who prefer right-wing parties and people who favor left-wing parties in terms of equality. Beyond that, humans are subject to change with age. This includes changes in the brain with age (Raz et al. 2005). Furthermore, life experiences increase with age. In addition, we examine the role of net income: the higher the income the less costly might generous behavior be. ${ }^{2}$

\footnotetext{
2 The following variables may be used in an exploratorexy analysis or for interpretation purposes (but they were not planned to be considered in our -ante specified research questions; besides in the description of the different kinds of subjects): the number of year chess-players have been playing for a chess club ("Chess activity"), the federal state the people are living in ("Federal state"), and the years of education ("Education").
}

Grüner-Khassine: Is there a link between wealth inequality and deception? - 


\subsection{Receiver behavior}

\section{To what extent does player 2 trust the message from player 1 in the reference scenario?}

Player 2 only knows the (potential) messages of player 1 in the benchmark scenario. This is cheap talk and should not play a role according to rational choice. Nevertheless, Gneezy (2005) found that almost $80 \%$ [78\%] of those who had the role of player 2 followed this message in his study. It can, therefore, be assumed that a large proportion of the subjects follows the message of player 1.

\section{How does the variation of the initial wealth affect the inclination to trust player 1 ?}

I. In treatment 1 , player 2 has an initial wealth of $€ 0$; player 1 has $€ 10$. Player 2 expects player 1 to be ready to give away some of the cake. In other words, player 2 expects player 1 to tend to act more honestly. Therefore, compared to the reference scenario, player 2 is more likely to follow the message of player 1 .

II. In treatment 2 , player 2 has an initial wealth of $€ 10$; player 1 has $€ 0$. Player 2 expects that player 1 considers the situation to be unfair and fears adverse discrimination. Therefore, player 2 is more probable (compared to the reference scenario) not to follow player 1's message (compared to the reference scenario).

\section{Do non-students rather than students tend to trust Player 1's message?}

A higher level of pro-sociality among the non-students can result in player 2 trusting the opponent more. Furthermore, it is conceivable that non-students are more willing to tolerate monetary disadvantageous inequality. Therefore, it could be assumed that non-students follow the messages more often than students do.

\section{What other determinants can explain the decision-making behavior of player 2 ?}

The first 3 research questions dealt with the variables expectation of the behavior of the opponent, treatment 2 , treatment 3 , and the population of interest (students vs. non-students). Now a bunch of other associations between the propensity to trust player 1 and the following variables will be examined: victim sensitivity, beneficiary sensitivity, religiosity, interpersonal trust, gender, political view, age, education, and net income.

[For a description of the variables, see Sender behavior, research question 4, paragraph 2]

\subsection{Market implications}

The highest market outcome (sum of the individual payoffs of player 1 and player 2) occurs (due to the design) when player 2 selects option A. Which scenario is most in line with Bentham's utilitarian greatest happiness principle? We expect player 1 to increasingly opt for option A in treatment 1 (compared to the baseline scenario) and player 2 to be inclined to follow this message. Compared to the benchmark scenario, presumably fewer subjects in the role of player 1 opt for option A in Treatment 2, but also fewer subjects trust the message. The overall effect is unclear and an empirical/experimental question. However, we suspect that the sender's renunciation of option A is greater than the decline in the receiver's trust. In other words, the market outcome would be greater for treatment 1 than for treatment 2 .

\begin{tabular}{|l|c|c|c|c|}
\hline \multicolumn{2}{|l|}{ Treatment } & Sender behavior & Receiver behavior & $\sum$ (Player 1 + Player 2) \\
\hline 1 & & Option A $\uparrow$ & Trust $\uparrow$ & $\mathrm{T} 1>\mathrm{T} 2$ \\
\hline
\end{tabular}

Grüner-Khassine: Is there a link between wealth inequality and deception? - 


\begin{tabular}{|l|l|l|l|l|}
\hline 2 & & Option A $\downarrow$ & Trust $\downarrow$ & \\
\hline
\end{tabular}

\section{Analysis plan / Approach to data analysis ${ }^{3}$}

To be admitted to the experiment, subjects must be 18 years or older. At the beginning of the study, subjects were asked whether they are students or non-students. For non-students to be considered it was additionally required that they are members of a chess club. The subjects were randomly assigned to a role (either player 1 or player 2), then randomly assigned to one of three groups (baseline, treatment 1 or treatment 2). Each subject only knows the group she has been assigned to. For all experimental subjects, information about the questions and statements as described in Table (XXX) are gathered. ${ }^{4}$

\footnotetext{
${ }^{3}$ This study has been approved by the German Association for Experimental Economic Research e.V. (Institutional Review Board Certificate No. sZXeRf5E).

${ }^{4}$ If several questions are combined (as for example with beneficiary sensitivit) the calculation follows the standard where the questions/treatments are taken from.
}

Grüner-Khassine: Is there a link between wealth inequality and deception? - 
Table: Summary of variables and their measurement

\begin{tabular}{|c|c|c|}
\hline Variable & Question / Statement & Values \\
\hline Student & Are you enrolled as a student at a university? & Yes $=1$, No $=0$ \\
\hline $\begin{array}{l}\text { Degree program } \\
\text { (if Student }=1 \text { ) }\end{array}$ & In which degree program are you enrolled? & $\begin{array}{l}\text { List of several degree programs }+ \text { option to add } \\
\text { another one }\end{array}$ \\
\hline Federal state & In which federal state do you live (main residence)? & $\begin{array}{l}\text { Saxony-Anhalt (1), Saxony (2), Thuringia (3), } \\
\text { Mecklenburg Western Pomerania (4), Branden- } \\
\text { burg (5), Berlin (6), Bavaria (7), Bremen (8), } \\
\text { Hesse (9), Hamburg (10), Baden-Württemberg } \\
\text { (11), Lower Saxony (12), Northrhine-Westphalia } \\
\text { (13), Rhineland Palatinate (14), Saarland (15), } \\
\text { Schleswig Holstein (16) }\end{array}$ \\
\hline Chess & Do you actively play chess in a club? & Yes $=1$, No $=0$ \\
\hline $\begin{array}{l}\text { Chess activity } \\
(\text { if Chess }=1)\end{array}$ & How many years have you been playing chess in a club? & \#years \\
\hline $\begin{array}{l}\text { Expectation Opponent } \\
\text { Version: Player } 1\end{array}$ & How many people out of 100 do you think follow your message? & {$[0 ; 100]$} \\
\hline $\begin{array}{l}\text { Expectation Opponent } \\
\text { Version: Player } 2\end{array}$ & $\begin{array}{l}\text { How many people out of } 100 \text { do you think have sent you an honest } \\
\text { message? }\end{array}$ & {$[0 ; 100]$} \\
\hline $\begin{array}{l}\text { Decision player } 1 \\
\text { [Situation } 1 \text { and } 2 \text {, respectively] }\end{array}$ & $\begin{array}{l}\text { Which message do you want to send to the other player? Option A or } \\
\text { Option B? }\end{array}$ & $\begin{array}{l}\text { Message } 1 \text { (i.e. honest one) }=1 \text {; message } 2 \text { (i.e. } \\
\text { dishonest one) }=0\end{array}$ \\
\hline Decision player 2 & $\begin{array}{l}\text { How do you decide yourself? Do you follow the other player's mes- } \\
\text { sage or do you decide differently? }\end{array}$ & $\begin{array}{l}1=\text { Yes, } I \text { follow the message; } 0=\mathrm{No} \text {, I do not } \\
\text { follow the message. }\end{array}$ \\
\hline Political view ${ }^{1}$ & $\begin{array}{l}\text { In politics people often talk about "left" and "right" to distinguish } \\
\text { different attitudes. If you think about your own political views: } \\
\text { Where would you place them? Please answer using the following } \\
\text { scale. } 0 \text { means "entirely left", } 10 \text { means "entirely right". You can } \\
\text { weigh your answers using the steps between } 0 \text { and } 10 \text {. }\end{array}$ & [0 entirely left; 10 entirely right] \\
\hline Gender $($ Female $=1)$ & What is your gender? & $0=$ Male, $1=$ Female, $2=$ Other \\
\hline Education & $\begin{array}{l}\text { Now it's about your years of education. Please add up the years of } \\
\text { school education, training, and university education (if applicable). } \\
\text { How many years do you have? }\end{array}$ & \#years \\
\hline Age & How old are you? & \#years \\
\hline Interpersonal trust ${ }^{2}$ & $\begin{array}{l}\text { 1) I am convinced that most people have good intentions. } \\
\text { 2) You can't rely on anyone these days. } \\
\text { 3) In general, people can be trusted. }\end{array}$ & $\begin{array}{l}\text { [“don't agree } \\
\text { at all" (1); "agree completely“ (5)] }\end{array}$ \\
\hline Religiosity $^{1}$ & Do you belong to a church or religious group? & Yes $=1$, No $=0$ \\
\hline Victim sensitivity $^{3}$ & $\begin{array}{l}\text { 1) It makes me angry when others are undeservingly better off } \\
\text { than me. } \\
\text { It worries me when I have to work hard for things that come } \\
\text { easily to others. }\end{array}$ & ["not at all" (1); "exactly“ (6)] \\
\hline Beneficiary sensitivity ${ }^{3}$ & $\begin{array}{l}\text { 1) I feel guilty when I am better off than others for no reason. } \\
\text { 2) It bothers me when things come easily to me that others have to } \\
\text { work hard for. }\end{array}$ & {$[,$, not at all“ $(1) ;$, ,exactly“ (6)] } \\
\hline Net income & Is your net income & $\begin{array}{l}\text { less than } € 750(=1), € 750 \text { up to less than } € 1500 \\
(=2), € 1500 \text { up to less than } € 2000(=3), € 2000 \text { up } \\
\text { to less than } € 2500(=4), € 2500 \text { up to less than } \\
€ 3000(=5) \text {, more than } € 3000(=6)\end{array}$ \\
\hline
\end{tabular}

1) SOEP-IS Group, 2018. SOEP-IS 2014 - Questionnaire for the SOEP Innovation Sample (Boost Sample, Update soep.is.2016.1). SOEP Survey Papers 518: Series A - Survey Instruments (Erhebungsinstrumente). Berlin: DIW Berlin/SOEP.

2) Beierlein, C., Kemper, C., Kovaleva, A.J. Rammstedt, B. (2014): Interpersonales Vertrauen (KUSIV3). Zusammenstellung sozialwissenschaftlicher Items und Skalen. doi:10.6102/zis37 [English version: https://www.gesis.org/fileadmin/_migrated/content_uploads/KUSIV3_en.pdf]

3) Schmitt, M., Baumert, A., Gollwitzer, M. Maes, J. (2010): The Justice Sensitivity Inventory: Factorial validity, location in the personality facet space, demographic pattern, and normative data. Social Justice Research 23: 211-238. [We use the following short scale: https://zis.gesis.org/skala/BeierleinBaumert-Schmitt-Kemper-Kovaleva-Rammstedt-Ungerechtigkeitssensibili\%C3\%A4t-Skalen-8-(USS-8)]

Grüner-Khassine: Is there a link between wealth inequality and deception? - 


\subsection{Description of the sample}

\section{- Characteristics of students and non-students}

First of all, we are interested to what extent non-students are more heterogeneous than students in terms of their socio-demographic characteristics and attitudes.

$\rightarrow$ Description of the students and non-students (mean values, standard deviations; fractions) with regard to the variables federal state*, chess activity, political view, gender**, education, age, interpersonal trust, religiosity, victim sensitivity, beneficiary sensitivity, net income [ $\rightarrow$ Table: Summary of variables and their measurement]. The differences between the two populations are primarily examined through differences in mean values and differences in standard deviations.

\#The description of the subjects does not include the expectations and decisions made in the 3 scenarios.

*If the subjects are from similar and a limited number of federal states, we provide the information in a table. Otherwise, we will describe it in the text of the manuscript.

**Data manipulation: If the number of the third gender is limited, we will acknowledge this but will drop these subjects in the regression analysis in order to compare male and female (there is no logical order in 3 different kinds of gender).

\section{- $\underline{\text { Sample Size }}$}

$\rightarrow$ We plan to recruit $\mathrm{N}=180$ students and $\mathrm{N}=180$ non-student chess-players. The total number of subjects per scenario and population ( $\mathrm{N}=30)$ results from budget constraints.

$\rightarrow$ Uncertainty about the success in recruiting non-students: we are ex-ante not sure if a sufficient number of non-student chess players could be recruited or if the spectrum of non-students has to be extended to subjects that are not playing chess in a club.

\subsection{Analysis plan of the research questions}

Primary outcome variables: Depending on the role of the experimental subject (either player 1 or player 2), the key variable of interest is either "decision player 1" (honest/dishonest message) or "decision player 2" (follow/not follow message).

We are mostly interested in the behavioral influence of the treatments on these primary outcome variables.

\subsubsection{Sender behavior}

\section{ad 1.) Honest behaviors in the reference scenarios}

-Share of subjects who are honest: option A in situation 1 (not in line with a rational money maximizer) and option $\mathrm{A}$ in situation 2 (in line with a rational money maximizer)

-Description of the subjects' expectations: Comparison of our results with Gneezy (2005), who found that the majority in the role of player 1 assumes that player 2 follows her message (Variable: Expectation Opponent Version: Player 1 vs. Gneezy 2005)

-Correlation of the subjects' decisions and expectations: We report the point-biserial correlation coefficient (Pearson 1909).

Grüner-Khassine: Is there a link between wealth inequality and deception? - 


\section{ad 2.) Honest behaviors in the treatment groups}

-Comparison of decisions in the treatments with decisions in the baseline scenarios for both decision situations 1 and 2 [Variable: Decision player 1 [Situation 1 and Situation 2, respectively]]. Nominal variables are compared with each other by using Cramér's V. Following Acock (2018), we use p-values from the chi-squared test.

-Comparison of expectations in the treatments with expectations in the baseline scenarios for both decision situations 1 and 2 [Variable: Expectation Opponent Version: Player 1]. Ordinal variables are compared with each other. To analyze the data we use Spearman's rho (but we also look at Kendall's tau-b, but only show the results if there are substantial discrepancies).

-Correlation between the subjects' decisions and expectations (for both treatments): We report the pointbiserial correlation coefficient (Pearson 1909).

\section{ad 3.) Honest behaviors: non-students vs students}

-Comparison of the decisions and expectations between non-students and students (pairwise comparisons: reference scenario student vs reference scenario non-student, treatment 1 student vs treatment 1 non-student, treatment 2 student vs treatment 2 non-student).

-For comparisons with nominal variables we rely on Cramér's V ( $\rightarrow$ decisions) and for ordinal variables ( $\rightarrow$ expectations) we refer to Spearman's rho (Kendall's tau-b).

\section{ad 4.) Honest behaviors: regression analysis}

Our regression analysis to better understand honest behaviors has three goals in mind. The first two of them have been tackled in correlation analysis before, but now we want to address it econometrically. We want to analyze...

(i) the role of expectations given different subject pools.

(ii) the role of treatment effects given different subject pools.

(iii) further determinants that can explain the tendency to be honest.

We plan to report the following regressions:

\begin{tabular}{|c|c|}
\hline Honest $_{\text {Sit A,B }}(Y=1)=\beta_{0}+\beta_{1} \bar{S}+\beta_{2}$ Expectation $_{1}[1]+\beta_{3} \bar{S}$ Expectation $[1]+u$ & 1 \\
\hline Honest $_{\text {Sit A,B }}(Y=1)=\beta_{0}+\beta_{1} \bar{S}+\beta_{2} T 1+\beta_{3} \bar{S} T 1+\beta_{4} T 2+\beta_{5} \bar{S} T 2+u$ & 2 \\
\hline $\begin{array}{l}\text { Honest }_{\text {Sit } A, B}(Y=1) \\
\qquad \begin{array}{l}\quad \beta_{0}+\beta_{1} \bar{S}+\beta_{2} T 1+\beta_{3} \bar{S} T 1+\beta_{4} T 2+\beta_{5} \bar{S} T 2+X_{p p} \beta+\bar{S} X_{p p} \beta+X_{\text {other }} \beta \\
\quad+\bar{S} X_{\text {other }} \beta+u\end{array}\end{array}$ & 3 \\
\hline
\end{tabular}

For each decision situation, we perform a logistic regression because the dependent variable honesty is dichotomous (if yes $=1$, otherwise 0 ). To increase the statistical power, we estimate a fully interactive model (i.e. interactions of the investigated independent variables with the population dummy variable). As coefficients of logistic regressions can only be interpreted with respect to signs, we report marginal effects

Grüner-Khassine: Is there a link between wealth inequality and deception? -

An experimental analysis of different subject pools 
to adequately describe the effect size (AME, state command: margins, dydx (exogenious variables)) (Cameron and Trivedi 2009). By comparing students with non-students, we set students as benchmark (i.e. $\bar{S}=$ $0)$. Thus, the main effect must be included with students.

We are considering the variables population (non-student, if $\bar{S}=1$ ), expectation opponent version: player 1 , and treatments $(T 1=$ treatment $1, T 2=$ treatment 2$)$. Furthermore, we address psychological and political control variables $\boldsymbol{X}_{\boldsymbol{p} \boldsymbol{p}}$ (political view, interpersonal trust, religiosity, victim sensitivity, beneficiary sensitivity) as well as some other control variables $\boldsymbol{X}_{\text {other }}$ (age, gender, net income). The questions/statements and their respective values are depicted in a separate table.

\#Exclusion criteria: We do not plan to include "chess acitivity" in years in the regression. Furthermore, the "degree program," education, and "federal state" might serve as information to interpret the findings, but not as explanatory variables in the first place. In a later, exploratory step, we might be interested in these variables (chess activity, degree program, federal state, education), but it is hard to specify it ex-ante. So we forego to consider it in our ex-ante specified analysis.

\section{Comments on regression 3:}

- Inflated p-values: Note that we look semi-exploratively at the determinants to explain the dependent variable. In other words, we ex-ante specify the variables that interest us. But we look more exploratively at the relationships that can be found in the data. Therefore, we would like to point out that the reported p-values are inflationary (due to multiple testing). However, our focus lies more on signs and effect sizes.

- Multicollinearity problem: We may have a multicollinearity problem. Multicollinearity occurs when two or more independent variables are highly correlated with each other. Concretely, it can be assumed that multicollinearity exists due to the many interaction terms. We test for multicollinearity by using variance inflation factors. What can be done in case of multicollinearity? Collecting additional data (which is often suggested in the literature) is not an option due to budget constraints. We would like to stick with the interactions of the population dummy variable. If the problem is only moderate (which can only be assessed after collecting the data), we do not intend to intervene and would live with it. Multicollineracy does not violate any of the Gauss Markov assumptions, which means that the test statistics remain valid. Though the coefficients have high standard errors (i.e. confidence intervals are valid, but large), there should not be a big problem since we do not primarily focus on p-values, but on signs and effect sizes.

It should be mentioned here that variables can also be perfectly correlated with each other (i.e. perfect collinearity). For example, students may be roughly half men and half women, but non-students could be entirely men. This would lead to perfect collinearity if an interaction variable between population and gender were generated. However, we do exclude perfect collinearity from our consideration.

\subsubsection{Receiver behavior}

\section{ad 1.) Trust the message from player 1 in the baseline scenario}

-Description of the expectations of the subjects (Variable: Expectation Opponent Version: Player 2)

Grüner-Khassine: Is there a link between wealth inequality and deception? - 
-Description of the proportation that follows message of player $1 \&$ comparison with Gneezy (2005) who has found that the vast majority follows the message (Variable: Decision player 2)

-Correlation of the subjects' decisions and expectations: We report the point-biserial correlation coefficient (Pearson 1909).

\section{ad 2.) Trust the message from player 1 in the treatment groups}

- Comparison of decisions in the treatments with decisions in the baseline scenario for both decision situations 1 and 2 [Variable: Expectation Opponent Version: Player 2]. Nominal variables are compared with each other by using Cramér's V. Following Acock (2018), we use p-values from the chi-squared test.

-Comparison of expectations in the treatments with expectations in the baseline scenario for both decision situations 1 and 2 [Variable: Expectation Opponent Version: Player 2]. Ordinal variables are compared with each other. To analyze the data we use Spearman's rho (but we also look at Kendall's tau-b, but only show the results if there are substantial discrepancies).

\section{ad 3.) Trust behaviors: non-students vs students}

-Comparison of the decisions and expectations between non-students and students (pairwise comparisons: reference scenario student vs reference scenario non-student, treatment 1 student vs treatment 1 non-student, treatment 2 student vs treatment 2 non-student).

-For comparisons with nominal variables we rely on Cramér's V ( $\rightarrow$ decisions) and for ordinal variables ( $\rightarrow$ expectations) we refer to Spearman's rho (Kendall's tau-b).

\section{ad 4.) Trust behaviors: regression analysis}

We examine determinants that can explain who is and who is not inclined to follow the opponent's message econometrically. For each decision situation, a logistic regression will be performed with the dichotomous dependent variable trust message (if yes $=1$, otherwise 0 ).

Argumentation in line with "ad 4.) Honest behaviors: other determinants"

The following specifications shall be considered (if meaningful). They differ from player 1 above only in the dependent variable (trust) and in the independent variable (expectations about player 1 instead of player 2):

\begin{tabular}{|c|c|}
\hline Trust $_{\text {Sit } A, B}(Y=1)=\beta_{0}+\beta_{1} \bar{S}+\beta_{2}$ Expectation $[2]+\beta_{3} \bar{S}$ Expectation $[2]+u$ & 1 \\
\hline Trust $_{\text {Sit } A, B}(Y=1)=\beta_{0}+\beta_{1} \bar{S}+\beta_{2} T 1+\beta_{3} \bar{S} T 1+\beta_{4} T 2+\beta_{5} \bar{S} T 2+u$ & 2 \\
\hline $\begin{aligned} \text { Trust }_{\text {Sit } A, B}(Y & =1) \\
& =\beta_{0}+\beta_{1} \bar{S}+\beta_{2} T 1+\beta_{3} \bar{S} T 1+\beta_{4} T 2+\beta_{5} \bar{S} T 2+X_{p p} \beta+\bar{S} X_{p p} \beta+X_{\text {other }} \beta \\
& +\bar{S} X_{\text {other }} \beta+u\end{aligned}$ & 3 \\
\hline
\end{tabular}

Grüner-Khassine: Is there a link between wealth inequality and deception? -

An experimental analysis of different subject pools 


\subsubsection{Market implications}

The decisions of player 2 (in both situations) determine the payoffs of both players. In both situations, a better market result could be achieved if option A would have been chosen. Thus, the number of A decisions is compared among the three scenarios and both populations. Cramér's V is used to statistically analyze dichotomous decisions.

Grüner-Khassine: Is there a link between wealth inequality and deception? - 